\title{
Associations Between Antioxidant Vitamin Status, Dietary Intake, and Retinol-binding Protein 4 Levels in Prepubertal Obese Children After 3-month Weight Loss Therapy
}

\author{
(D) Joanna Gajewska1, (D) Jadwiga Ambroszkiewicz¹, (D) Katarzyna Szamotulska², (D) Witold Klemarczyk³, (D) Halina Weker³, \\ (D) Magdalena Chełchowska1
}

1 Institute of Mother and Child, Department of Screening and Metabolic Diagnostics, Warsaw, Poland

2 Institute of Mother and Child, Department of Epidemiology and Biostatistics, Warsaw, Poland

3 Institute of Mother and Child, Department of Nutrition, Warsaw, Poland

\begin{abstract}
What is already known on this topic?
Oxidative stress conditions in obese subjects are associated with abnormal serum pro- and anti-inflammatory adipokines. Antioxidant vitamins may be important factors in the treatment and prevention of obesity and obesity-related disorders.
\end{abstract}

\section{What this study adds?}

An increased risk of vitamin E deficiency due to decreased vitamin E intake may occur in children losing weight during lifestyle intervention. Changes in body mass index value may influence changes in retinol-binding protein 4 concentrations and consequently the vitamin A status in prepubertal obese children after therapy.

\section{Abstract}

Objective: Adiposity is associated with increased oxidative stress, leading to changed fat-soluble vitamin concentrations. The aim of this study was to determine whether weight loss alters fat-soluble vitamin status and whether these alterations are associated with dietary intake, anthropometric parameters and adipokines in obese children.

Methods: Vitamin A and E concentrations were measured using high-pressure liquid chromatography in 60 obese children before and after weight loss therapy. Retinol-binding protein 4 (RBP4), leptin, soluble leptin receptor (sOB-R), and high molecular weight adiponectin concentrations were determined by immunoenzymatic assays.

Results: The intake of vitamin E was lower in obese children with weight loss after therapy ( $p=0.038)$. In this group, an increase was found in the vitamin A/lipids $(p=0.022)$ and the vitamin E/lipids $(p=0.008)$ ratios but due to the reduction in triglyceride levels. In the obese group, changes in vitamin E level were positively correlated with changes in dietary vitamin $E(p=0.017)$ and the leptin/ sOB-R ratio $(p=0.046)$. Changes in vitamin A level were positively correlated with changes in dietary vitamin $A(p=0.001)$ and $R B P 4$ concentration $(p=0.023)$. Associations between changes in RBP4 level with the changes in body mass index (BMI) ( $p=0.011$ ) and total cholesterol concentration ( $p=0.023$ ) but not with changes in vitamin A concentration were found in the obese after therapy.

Conclusion: An increased risk of vitamin E deficiency may occur in children losing weight during lifestyle intervention. Changes in BMI value may influence changes in RBP4 concentrations and consequently the vitamin A status in obese children after therapy.

Keywords: Vitamin A, vitamin E, retinol-binding protein 4, prepubertal period, weight loss therapy

\section{Introduction}

Obesity is associated with a subclinical inflammatory condition characterized by an increase of proinflammatory adipokines, which may contribute to increase oxidative stress $(1,2)$. Scientific evidence suggests that antioxidant vitamins may be important factors in the treatment and prevention of obesity and obesity-related disorders. Fat-
Address for Correspondence: Joanna Gajewska MD, Institute of Mother and Child, Department of Screening and Metabolic Diagnostics, Warsaw, Poland Phone: +48/22/3277260 E-mail: joanna.gajewska@imid.med.pl ORCID: orcid.org/0000-0002-1349-0155
Conflict of interest: None declared Received: 28.08.2020 Accepted: 03.11.2020

${ }^{\circ}$ Copyright 2021 by Turkish Pediatric Endocrinology and Diabetes Society

The Journal of Clinical Research in Pediatric Endocrinology published by Galenos Publishing House. 
soluble vitamins, which act as free radical scavengers, belong to the most important components of the antioxidant cell defence system. Vitamin A (retinol) is a micronutrient required for growth and development, conceivably affecting lipid metabolism, energy regulation and body composition (3). Vitamin $\mathrm{E}$ is most commonly found in the form of alphatocopherol and acts as a peroxyl scavenger, thus preventing membrane lipid oxidation (4). Some studies in young populations have shown positive associations between these vitamin levels and obesity (5) but other studies suggest that fat deposition, chronic inflammation and oxidative stress are associated with deficiencies in fat-soluble vitamin concentrations $(6,7)$. Lower values of fat-soluble vitamins in American and European populations of obese children compared with normal-weight controls were observed $(8,9)$. These alterations may also result from an unbalanced diet in overweight and obese individuals. It was observed that dietary antioxidant intakes were lower among some populations of obese children $(10,11)$, however in others they did not differ between normal-weight, overweight, and obese children (12). Diet is an important factor in the modulation of oxidative stress and the inflammatory process, and an antioxidant-rich diet is associated with a reduced risk of diseases resulting from obesity $(13,14)$.

High oxidative stress conditions in obese subjects are associated with raised levels of serum pro-inflammatory adipokines, such as leptin, and decreased anti-inflammatory adipokines, such as adiponectin especially its high molecular weight (HMW) form, which can influence insulin sensitivity (1). In obese patients chronic endoplasmic reticulum stress decreases the amount of soluble leptin receptor (SOB-R) due to diminished membrane leptin receptor (OB-R) expression. In consequence, endoplasmic reticulum stress can limit the inhibitory effect of the leptin receptor on leptin function, inducing a leptin resistant state in obesity. Oxidative stress is also observed in obese children with increased levels of retinol-binding protein 4 (RBP4), a hepatocyte and adipocyte derived adipokine, thus potentially providing the link between obesity and its consequences due to the induction of mitochondrial dysfunction and vascular oxidative damage (15). RBP4 is also a plasma retinol transporter that carries retinol from the liver to the periphery, while very little plasma RBP4 is derived from adipose tissue. In obese subjects, RBP4 levels decrease during weight loss intervention and this reduction is correlated with the magnitude of the decrease in inflammatory markers, triglycerides, insulin, and the Homeostasis Model Assessment index (16). However, studies concerning the relation between RBP4 concentrations and vitamin A intake and plasma concentration are inconclusive $(17,18)$. Therefore, the aim of this study was to determine: (a) the status of vitamins $\mathrm{A}$ and $\mathrm{E}$ in prepubertal obese and non-obese children; (b) whether weight loss after a 3-month lifestyle intervention alters fat-soluble vitamin status; and (c) whether these alterations are associated with dietary intake, anthropometric parameters, and pro- and antiinflammatory adipokines in obese children.

\section{Methods}

\section{Patients}

One hundred and five prepubertal children, aged 5-10 years, were recruited from a group of consecutive patients seeking dietary counseling in the Department of Nutrition at the Institute of Mother and Child in Warsaw. The obese group consisted of 60 children with a body mass index (BMI) $Z$-score of $>2$. The exclusion criteria were: pubertal and postpubertal period; the presence of endocrine disorders or genetic syndromes, including syndromic obesity; acute or chronic medical conditions; intake of medications that could affect growth, pubertal development, nutritional or dietary status; and refusing consent to participate. The control group consisted of 45 prepubertal non-obese children (BMI Z-score $<-1+1>$ ) within the same age range as the obese group with an adequate nutritional or dietary status according to the recommendations of Kułaga et al (19) and Jarosz (20). This control group consisted of children without either acute or chronic disorders, were not taking any medications that could affect their development or nutritional or dietary status. Pubertal stage was determined according to the Tanner scale. All obese and non-obese children were Tanner stage 1 . The study was performed in accordance with the Helsinki Declaration for Human Research, and the study protocol was approved (No.9/18) by the Ethics Committee of the Institute of Mother and Child in Warsaw, Poland. All parents gave their informed consent for the study.

\section{Dietary Intervention}

The weight loss therapy used in this study was based on a calorie restricted diet of 1200-1400 kcal/day (10-30\% caloric deficit) and was composed of $20 \%$ protein, $30 \%$ fat and $50 \%$ carbohydrates for approximately $10 \%$ weight loss in three months (21). Patients had 3-5 meals every day. For each obese child, parents received nutritional guidelines including: (a) low-energy diet plan, including examples of daily menu and portion sizes of some products; (b) daily recommended consumption of products from various groups in grams, paying special attention to the sources of vitamins, including $\mathrm{A}$ and $\mathrm{E}$, and minerals in accordance with the daily requirement depending on age; and (c) a list of products with different energy values. 
Two weeks before the child was due to visit the department of nutrition, a 14-day food diary was completed at home using a questionnaire and brought to the Institute. The parents had previously been trained by a nutritionist to provide reliable estimates of diary intake. In the nutrition department, nutritionists carried out an interview concerning the family and environmental conditions of the children, their nutritional behavior and food preferences, and checked the diary in the presence of the child and his/ her parents. The nutritionist asked for detailed information about the foods and drinks recorded, such as portion sizes and preparation methods. When necessary the portion size records were corrected during the visit. This was done by the nutritionist on the basis of an interview with the parents using a photo album of products and dishes presenting meal portion sizes (22). The three-day methodology was used according to the guide on nutrition research to assess the intake in the children's dietary habits (23). Two weekdays and one weekend day before (visit T0) and after three months of therapy (visit T3), were entered into nutritional analysis software (Dieta $5^{\circledR}$, National Food and Nutrition Institute, Warsaw, Poland) to evaluate the average daily energy intake and the percentage of energy intake from protein, fat and carbohydrates, as well as vitamin (A, E) intakes in the children's diets (24). The data for each child were compared to the recommendations for the appropriate age and gender. The age- and sex-specific percentages of Estimated Energy Requirement (EER) for total energy intake, Estimated Average Requirement (EAR) for vitamin $\mathrm{A}$, and adequate intake (AI) for vitamin $\mathrm{E}$ were calculated for each obese child before and after the three-month therapy according to the recommendations of Jarosz (20). In addition, these values were calculated once for each nonobese child. The participants in the present study did not receive supplements, except for standard supplementation with vitamin D.

\section{Anthropometric Measurements}

Body height was measured using a standing stadiometer and recorded with a precision of $1 \mathrm{~mm}$. Body weight was assessed, unclothed, to the nearest $0.1 \mathrm{~kg}$ with a calibrated balance scale. BMI was calculated as body weight divided by height squared $\left(\mathrm{kg} / \mathrm{m}^{2}\right)$. The BMI of each individual was converted to the BMI Z-score for the child's age and sex using Polish reference tables (19). Body composition was measured by dual-energy X-ray absorptiometry using Lunar Prodigy (General Electric Healthcare, Madison, WI, USA) with pediatric software, version 9.30.044. All subjects were measured with the same equipment, using standard positioning techniques.

\section{Biochemical Analyses}

Venous blood samples were collected between 8:00 and 10:00 am after an overnight fast, and centrifuged at $1000 \mathrm{x}$ $\mathrm{g}$ for $10 \mathrm{~min}$ at $4^{\circ} \mathrm{C}$. Serum specimens were stored at $-70{ }^{\circ} \mathrm{C}$ prior to assay. Vitamin A and $\mathrm{E}$ in serum were determined using an Ultra High Performance Liquid Chromatography system (Nexera LC30A, Shimadzu, Kyoto, Japan) integrated with a 190-800 nm UV-VIS detector (SPD20AV, Shimadzu, Kyoto, Japan) (25). The detection of alpha-tocopherol and retinol was carried out at $290 \mathrm{~nm}$ and $320 \mathrm{~nm}$, respectively. The retinyl acetate, alpha-tocopherol and all trans retinol (Sigma Aldrich, St Louis, MO, USA) were used as a standard. The concentrations of vitamins were expressed in $\mu \mathrm{mol} / \mathrm{L}$.

A commercially available enzyme-linked immunosorbent assay (ELISA) kit was used to determine the concentration of RBP4 (Immundiagnostic AG, Bensheim, Germany), which had an inter-assay variation (CV\%) of less than $10 \%$. The concentrations of leptin and SOB-R were also measured by commercial ELISA kits (DRG Diagnostics, Marburg, Germany). Inter-assay CVs were $5.3 \%$ and $3.3 \%$ for leptin and SOB-R, respectively. Serum levels of HMW adiponectin were determined using an ELISA kit (ALPCO Diagnostics, Salem, NH, USA). Inter-assay variation was $5.7 \%$ for HMW adiponectin. Total cholesterol, low-density lipoprotein (LDL) cholesterol and high-density lipoprotein (HDL) cholesterol, and triglyceride levels were measured using standard methods (Roche Diagnostics, Switzerland, Basel). To reduce inter-assay variance, the samples obtained before and after therapy were analyzed in one assay.

\section{Statistical Analyses}

Statistical analysis was performed using IBM SPSS v.25.0 software (SPSS Inc., Chicago, IL, USA). The results are presented as mean \pm standard deviation for normally distributed data or medians and interquartile range $\left(25^{\text {th }}\right.$ $75^{\text {th }}$ percentiles) for non-normally distributed variables. The Kolmogorov-Smirnov test was used for evaluating distribution for normality. Differences in anthropometric characteristics and biochemical parameters of obese and non-obese children were assessed using Student's t-test for normally distributed data and the non-parametric MannWhitney test for non-normally distributed variables.

Changes in BMI Z-score, body composition and biochemical parameters were expressed as delta variables, calculated by subtracting the values at baseline (T0) from the values measured after three months of therapy (T3). Obese children were categorized into two subgroups according to the magnitude of BMI Z-score change during the intervention: children with weight loss ( $\triangle \mathrm{BMI} Z$-score $\leq-0.5, \mathrm{n}=37$ ); and children without weight loss ( $\triangle \mathrm{BMI} Z$-score $>-0.5, n=23$ ). 
The correlation coefficients between changes in the serum concentrations of vitamins A, E and RBP4 and changes in the anthropometric, dietary and biochemical parameters after therapy were calculated using Spearman's correlations.

The univariate and stepwise forward linear regression with the changes of serum concentration of RBP4 as dependent variables were used to examine the potential impact of the anthropometric and biochemical variables. A $p<0.05$ was considered to be statistically significant.

\section{Results}

The median value of BMI was over $50 \%$ higher in obese patients than in controls (Table 1). The obese children had a four-fold greater fat mass, a two-fold higher percentage of fat mass, approximately $30 \%$ greater lean mass, and a $50 \%$ greater total bone mineral content compared with non-obese subjects. The values of vitamin A, RBP4, and the RBP4/vitamin A ratio were significantly higher in obese than non-obese children by $20 \%, 35 \%$, and $25 \%$, respectively. The levels of vitamin $\mathrm{E}$ and the vitamin E/lipids (the sum of total cholesterol and triglycerides) ratio were similar in both study groups. In obese children the leptin/sOB-R ratio was more than 10-fold higher but the value of HMW adiponectin was significantly lower by $30 \%$ compared to controls.

The daily energy intake was significantly higher in obese children compared to controls before the intervention (Table 1). The obese children had higher intake of carbohydrate and fat than normal-weight subjects, but the proportions of protein, fat, and carbohydrates in the daily energy intake were similar in both groups. The diet of obese children contained a higher intake of vitamin $\mathrm{E}$ than that of normalweight children $(p<0.02)$. However, the median value of AI percentage for vitamin $\mathrm{E}$ in obese and non-obese children were lower by about $10 \%$ and $20 \%$, respectively, than the recommended value for this vitamin by Jarosz (20). A similar intake of vitamin A and percentage of EAR for this vitamin were observed in both studied groups and these values were appropriate for the age group (20).

In the whole obese group before therapy, positive relations between vitamin A levels and dietary vitamin A $(r=0.411$; $p<0.01)$, total cholesterol $(r=0.318 ; p<0.02)$ and LDLcholesterol levels $(r=0.269 ; p<0.05)$ were found. The value of vitamin E correlated negatively with BMI value $(r=-0.347$; $p<0.01)$, leptin level $(r=-308 ; p<0.02)$ and positively with total cholesterol $(r=0.420 ; p<0.001)$ and LDL-cholesterol $(r=0.330 ; p<0.02)$.

After the three-month intervention, a significant increase was found in the vitamin A/lipids and the vitamin E/lipids ratios in patients with weight loss ( $\triangle \mathrm{BMI}$ Z-score $\leq-0.5$ ) (Table 2). These parameters did not change in the group without weight loss after therapy. In obese children with weight loss the leptin/sOB-R ratio decreased and the HMW adiponectin level increased but leptin/sOB-R ratio was still higher $(p<0.001)$ and the HMW adiponectin level was lower $(p<0.01)$ compared with the control group.

The group of children who lost weight reduced their energy intake and percentage of EER during the therapy $(p<0.001)$, as opposed to the group without weight loss (Table 2). In addition, the percentage of energy intake from proteins increased significantly in obese children with weight loss, whereas the percentage of energy intake from fat increased significantly in obese children without weight loss after intervention. In contrast to children without weight loss after therapy, in children with weight loss the intakes of carbohydrate and fat were significantly lower during this intervention.

The values of vitamin A intake and the EAR percentage for this vitamin after the three-month therapy were lower but statistically insignificant in both groups of obese children (Table 2). The intake of vitamin $\mathrm{E}$ and the AI percentage for this vitamin were significantly lower $(p=0.038$ and $p=0.02$, respectively) in children with weight loss in contrast to those without weight loss. In addition, median values of the AI percentage for vitamin $\mathrm{E}$ in the group with and without weight loss were lower than the recommendation by about $25 \%$ and $10 \%$, respectively (20).

Changes in vitamin A level were positively correlated with changes in dietary vitamin A and vitamin E, concentrations of vitamin E, RBP4, leptin, and lipids (Table 3). Changes in vitamin E level were positively correlated with changes in dietary vitamin E, the leptin/sOB-R ratio, and lipid levels. Changes in RBP4 level after the three-month therapy were positively correlated with changes in BMI value, concentrations of vitamin A, leptin and lipids.

In the stepwise forward linear regression with changes in RBP4 level after three months of therapy as a dependent variable and changes in BMI values, vitamin A, leptin and total cholesterol concentrations as independent variables, only changes of BMI values $(p<0.02)$ as well as changes in total cholesterol concentrations $(p<0.05)$ in the obese group after therapy were found to be statistically significant (Table 4).

\section{Discussion}

Fat-soluble vitamin deficiency is more common in children than adults, probably because they have limited stores 


\begin{tabular}{|c|c|c|c|}
\hline Parameter* & Obese children $N=60$ & Non-obese children $\mathrm{N}=45$ & $p$ value \\
\hline Age (years) & $7.9 \pm 1.4$ & $7.3 \pm 1.8$ & 0.066 \\
\hline Boys (\%) & 50.0 & 50.0 & 0.820 \\
\hline Height (cm) & $134 \pm 10$ & $123 \pm 11$ & $<0.001$ \\
\hline Height Z-score & $1.00 \pm 1.10$ & $-0.27 \pm 0.98$ & $<0.001$ \\
\hline Weight (kg) & $41.8(36.6-55.0)$ & $23.0(18.8-28.4)$ & $<0.001$ \\
\hline BMI $\left(\mathrm{kg} / \mathrm{m}^{2}\right)$ & $24.1(21.8-26.5)$ & $15.4(14.5-16.3)$ & $<0.001$ \\
\hline BMI Z-score & $3.19(2.41-4.51)$ & $-0.36(-0.85-0.03)$ & $<0.001$ \\
\hline \multicolumn{4}{|l|}{ Body composition } \\
\hline Fat mass (\%) & $41.7 \pm 5.1$ & $20.9 \pm 8.2$ & $<0.001$ \\
\hline Fat mass (kg) & $16.1(13.6-23.0)$ & $4.1(2.8-6.6)$ & $<0.001$ \\
\hline Lean mass (kg) & $24.3 \pm 4.4$ & $18.2 \pm 3.5$ & $<0.001$ \\
\hline Total BMC (kg) & $1.2(1.0-1.5)$ & $0.8(0.7-1.0)$ & $<0.001$ \\
\hline \multicolumn{4}{|l|}{ Biochemical parameters } \\
\hline Vitamin A $(\mu \mathrm{mol} / \mathrm{L})$ & $1.47(1.20-1.87)$ & $1.21(1.07-1.34)$ & 0.041 \\
\hline RBP4 (mg/L) & $22.3 \pm 6.2$ & $16.4 \pm 4.3$ & $<0.001$ \\
\hline RBP4/Vitamin A & $0.745 \pm 0.295$ & $0.588 \pm 0.192$ & 0.012 \\
\hline Vitamin A/lipids ( $\mu \mathrm{mol} / \mathrm{mmol})$ & $0.29(0.21-0.35)$ & $0.24(0.22-0.27)$ & 0.199 \\
\hline Vitamin E ( $\mu \mathrm{mol} / \mathrm{L})$ & $17.7(13.4-22.8)$ & $18.7(16.3-20.4)$ & 0.521 \\
\hline Vitamin E/lipids ( $\mu \mathrm{mol} / \mathrm{mmol})$ & $3.53(2.57-4.18)$ & $3.60(3.29-4.16)$ & 0.199 \\
\hline Leptin/sOB-R & $0.80(0.35-1.44)$ & $0.06(0.03-0.11)$ & $<0.001$ \\
\hline HMW adiponectin $(\mu \mathrm{g} / \mathrm{mL})$ & $3.70 \pm 1.60$ & $5.20 \pm 2.70$ & 0.002 \\
\hline Total cholesterol (mg/dL) & $171.0 \pm 28.3$ & $172.7 \pm 24.7$ & 0.755 \\
\hline HDL-cholesterol (mg/dL) & $51.1 \pm 11.3$ & $64.4 \pm 12.6$ & $<0.001$ \\
\hline LDL-cholesterol (mg/dL) & $101.0(93.0-121.0)$ & $99.5(82.0-117.0)$ & 0.216 \\
\hline Triglycerides (mg/dL) & $81.5(57.5-122.8)$ & $54.5(43.0-76.3)$ & $<0.001$ \\
\hline \multicolumn{4}{|l|}{ Dietary intake** } \\
\hline Energy (kcal/day) & $1634.5(1381.6-2004.2)$ & $1488.7(1244.6-1722.2)$ & 0.020 \\
\hline Energy (of EER \%) & $93.5(76.1-110.9)$ & $86.9(68.4-111.3)$ & 0.329 \\
\hline Protein (of energy intake \%) & $13.8 \pm 2.7$ & $14.7 \pm 2.9$ & 0.104 \\
\hline Carbohydrate (of energy intake \%) & $52.4 \pm 7.7$ & $51.8 \pm 6.3$ & 0.662 \\
\hline Fat (of energy intake \%) & $33.8 \pm 6.8$ & $32.5 \pm 5.6$ & 0.833 \\
\hline Protein (g/day) & $60.5 \pm 21.6$ & $53.9 \pm 15.1$ & 0.105 \\
\hline Carbohydrate (g/day) & $246.2 \pm 89.0$ & $203.1 \pm 60.2$ & 0.010 \\
\hline Fat (g/day) & $68.4 \pm 25.9$ & $56.7 \pm 18.1$ & 0.014 \\
\hline Vitamin A ( $\mu \mathrm{g} /$ day) & $723.0(515.6-1192.1)$ & $684.5(441.6-882.0)$ & 0.108 \\
\hline Vitamin A (EAR \%) & $193.8(145.5-340.6)$ & $193.9(137.5-260.0)$ & 0.226 \\
\hline Vitamin E (mg/day) & $6.4(4.9-8.9)$ & $5.6(3.8-6.7)$ & 0.016 \\
\hline Vitamin E (AI\%) & $88.6(64.2-119.5)$ & $80.2(55.7-102.5)$ & 0.053 \\
\hline
\end{tabular}

* Results are presented as means \pm standard deviations for normally distributed data, or medians and interquartile ranges $\left(25^{\text {th }}-75^{\text {th }}\right.$ percentiles) for nonnormally distributed variables.

* * Recommended daily energy and nutrients intakes (4-6/7-9 years) according to Jarosz (20): energy (1400/1800 kcal/day), protein (10-20\%), carbohydrate (45$65 \%$ ), fat (20-35\%), protein (16/23 g/day), carbohydrate (130/130 g/day), fat (31-54/40-70 g/day), vitamin A (300/350 g/day), vitamin E (6/7 g/day), BMC: bone mineral content, BMI: body mass index, HMW: adiponectin, high molecular weight adiponectin, sOB-R: soluble leptin receptor, RBP4: retinolbinding protein 4, HDL: high-density lipoprotein, LDL: low-density lipoprotein; lipids, the sum of total cholesterol and triglycerides, EER: Estimated Energy Requirement, EAR: Estimated Average Requirement, AI: adequate intake

and grow rapidly, which promotes the appearance of the symptoms of this vitamin deficiency (8). Some authors observed vitamin A insufficiency in obese children and adolescents due to an unbalanced diet (6), but others found 
Table 2. Demographic and biochemical characteristics and dietary intake of prepubertal obese children with and without weight loss after therapy

\begin{tabular}{|c|c|c|c|c|c|c|c|c|}
\hline \multirow[b]{2}{*}{ Parameter } & \multicolumn{4}{|c|}{$\begin{array}{l}\text { Obese children with weight loss } \\
(\Delta \mathrm{BMI} Z \text {-score } \leq-0.5), \mathrm{n}=37\end{array}$} & \multicolumn{4}{|c|}{$\begin{array}{l}\text { Obese children without weight loss } \\
(\Delta \mathrm{BMI} Z \text {-score }>-0.5), \mathrm{n}=23\end{array}$} \\
\hline & $\mathrm{T}_{0}$ & $\mathrm{~T}_{3}$ & $\Delta(\mathrm{IQR})$ & $\mathbf{p}_{\Delta=0}$ & $\mathrm{~T}_{0}$ & $\mathrm{~T}_{3}$ & $\Delta(\mathrm{IQR})$ & $\mathbf{p}_{\Delta=0}$ \\
\hline Age (years) & 8.3 & 8.8 & $0.3(0.2-0.3)$ & $<0.001$ & 7.5 & 7.8 & $0.3(0.2-0.3)$ & $<0.001$ \\
\hline Boys (\%) & 48.6 & & & & 52.2 & & & \\
\hline Height (cm) & 137 & 138 & $2(1-2)$ & $<0.001$ & 130 & 131 & $2(1-2)$ & $<0.001$ \\
\hline Height Z-score & 1.04 & 0.97 & $0.24(-0.38-0.32)$ & 0.411 & 0.75 & 0.76 & $0.29(0.02-0.34)$ & 0.046 \\
\hline Weight (kg) & 45.3 & 40.6 & $-3.0[(-4.9)-(-1.8)]$ & $<0.001$ & 37.8 & 39.3 & $0.7(-0.2-1.9)$ & 0.016 \\
\hline BMI $\left(\mathrm{kg} / \mathrm{m}^{2}\right)$ & 24.1 & 22.5 & $-2.1[(-3.2)-(-1.5)]$ & $<0.001$ & 24.1 & 24.2 & $0.0(-0.5-0.2)$ & 0.529 \\
\hline BMI Z-score & 3.17 & 2.11 & $\begin{array}{l}-1.03 \\
{[(-1.45)-(-0.63)]}\end{array}$ & $<0.001$ & 3.21 & 3.09 & $-0.01(-0.20-0.07)$ & 0.604 \\
\hline \multicolumn{9}{|l|}{ Biochemical parameters } \\
\hline Vitamin A $(\mu \mathrm{mol} / \mathrm{L})$ & 1.48 & 1.44 & $0.07(-0.17-0.31)$ & 0.458 & 1.49 & 1.73 & $0.08(-0.25-0.47)$ & 0.397 \\
\hline RBP4 (mg/L) & 23.2 & 19.9 & $-1.3(-7.5-3.0)$ & 0.065 & 19.3 & 19.2 & $-1.3(-3.2-2.6)$ & 0.432 \\
\hline RBP4/Vitamin A & 0.72 & 0.65 & $-0.07(-0.22-0.11)$ & 0.062 & 0.56 & 0.54 & $-0.07(-0.17-0.08)$ & 0.134 \\
\hline $\begin{array}{l}\text { Vitamin A/lipids ( } \mu \mathrm{mol} / \\
\mathrm{mmol} \text { ) }\end{array}$ & 0.29 & 0.30 & $0.03(-0.02-0.09)$ & 0.022 & 0.29 & 0.34 & $0.05(-0.05-0.12)$ & 0.082 \\
\hline Vitamin E ( $\mu \mathrm{mol} / \mathrm{L})$ & 16.7 & 16.5 & $0.4(-1.7-4.2)$ & 0.192 & 18.4 & 18.7 & $0.9(-6.4-4.5)$ & 1.000 \\
\hline $\begin{array}{l}\text { Vitamin E/lipids ( } \mu \mathrm{mol} / \\
\mathrm{mmol} \text { ) }\end{array}$ & 3.28 & 3.35 & $0.42(-0.14-0.99)$ & 0.008 & 3.74 & 3.80 & $0.43(-0.27-0.81)$ & 0.157 \\
\hline Leptin/sOB-R & 0.84 & 0.29 & $-0.46[(-0.92)-(-0.11)]$ & $<0.001$ & 0.69 & 0.57 & $-0.11(-0.27-0.30)$ & 0.687 \\
\hline HMW adiponectin $(\mu \mathrm{g} / \mathrm{mL})$ & 3.50 & 4.00 & $0.30(0.00-1.2)$ & 0.002 & 3.60 & 3.80 & $0.1(-1.2-0.8)$ & 0.876 \\
\hline Total cholesterol (mg/dL) & 161.5 & 159.0 & $-4.5(-23.8-10.8)$ & 0.328 & 171.0 & 165.0 & $-13.0[(-26.0)-(-1.0)]$ & 0.016 \\
\hline HDL-cholesterol (mg/dL) & 50.5 & 51.5 & $1.0(-6.0-6.8)$ & 0.765 & 51.0 & 46.0 & $-1.0(-7.0-3.0)$ & 0.544 \\
\hline LDL-cholesterol (mg/dL) & 98.5 & 98.5 & $-5.5(-20.8-6.8)$ & 0.124 & 113.0 & 105.0 & $-13.0(-21.0-9.0)$ & 0.168 \\
\hline Triglycerides (mg/dL) & 91.0 & 71.5 & $-8.0(-58.5-6.8)$ & 0.020 & 72.0 & 78.0 & $2.0(-27.0-29.0)$ & 0.946 \\
\hline \multicolumn{9}{|l|}{ Dietary intake } \\
\hline Energy (kcal/day) & 1653.8 & 1199.2 & $-438.5(-831.7-0.0)$ & 0.001 & 1925.6 & 1760.7 & $-58.6(-449.7-0.0)$ & 0.438 \\
\hline Energy (of EER \%) & 91.9 & 66.6 & $-26.2[(-46.2)-(-3.7)]$ & $<0.001$ & 107.0 & 97.8 & $-3.3(-28.5-0.0)$ & 0.438 \\
\hline Proteins (of energy intake \%) & 13.9 & 17.2 & $2.0(-0.2-5.9)$ & 0.014 & 13.4 & 14.3 & $0.5(0.0-2.3)$ & 0.375 \\
\hline $\begin{array}{l}\text { Carbohydrates (of energy } \\
\text { intake \%) }\end{array}$ & 52.8 & 51.2 & $-0.1(-5.4-4.8)$ & 0.849 & 56.0 & 50.0 & $-5.1(-10.0-0.0)$ & 0.078 \\
\hline Fat (of energy intake \%) & 32.6 & 31.4 & $-2.8(-8.7-5.0)$ & 0.166 & 31.7 & 36.1 & $4.7(0.0-7.7)$ & 0.047 \\
\hline Protein (g/day) & 61.7 & 48.9 & $-5.13(-27.1-9.7)$ & 0.092 & 61.7 & 58.2 & $0.0(-6.3-0.8)$ & 0.906 \\
\hline Carbohydrate (g/day) & 252.0 & 154.1 & $-39.9[(-96.7)-(-8.6)]$ & 0.002 & 266.7 & 250.1 & $-19.0(-98.9-0.0)$ & 0.203 \\
\hline Fat (g/day) & 61.9 & 43.4 & $-21.3(-49.9-0.0)$ & 0.002 & 69.1 & 69.1 & $0.0(-3.9-3.9)$ & 0.938 \\
\hline Vitamin A (mg) & 616.4 & 538.2 & $-75.1(-373.6-175.4)$ & 0.427 & 732.2 & 644.2 & $0.0(-447.2-167.7)$ & 0.906 \\
\hline Vitamin A (EAR \%) & 172.3 & 153.8 & $-35.9(-120.5-50.1)$ & 0.329 & 244.1 & 186.8 & $0.0(-127.8-55.9)$ & 0.938 \\
\hline Vitamin E (mg) & 6.9 & 5.2 & $-1.5(-4.5-0.3)$ & 0.038 & 5.6 & 6.0 & $0.1(0.0-1.5)$ & 0.219 \\
\hline Vitamin E (AI \%) & 88.6 & 74.3 & $-22.1(-63.8-4.4)$ & 0.020 & 86.4 & 90.1 & $1.22(0.0-25.6)$ & 0.219 \\
\hline
\end{tabular}

elevated serum retinol associated with dyslipidemia, BMI, Albuquerque et al (26), we found higher concentrations of adiposity and abdominal fat mass $(7,26,27)$. Similar to vitamin A and well as vitamin A/lipids and RBP4/lipids in 
Table 3. Associations between changes in fat-soluble vitamin and retinol-binding protein 4 concentrations and changes in anthropometric and biochemical parameters in obese children after three-month therapy $(\Delta)$

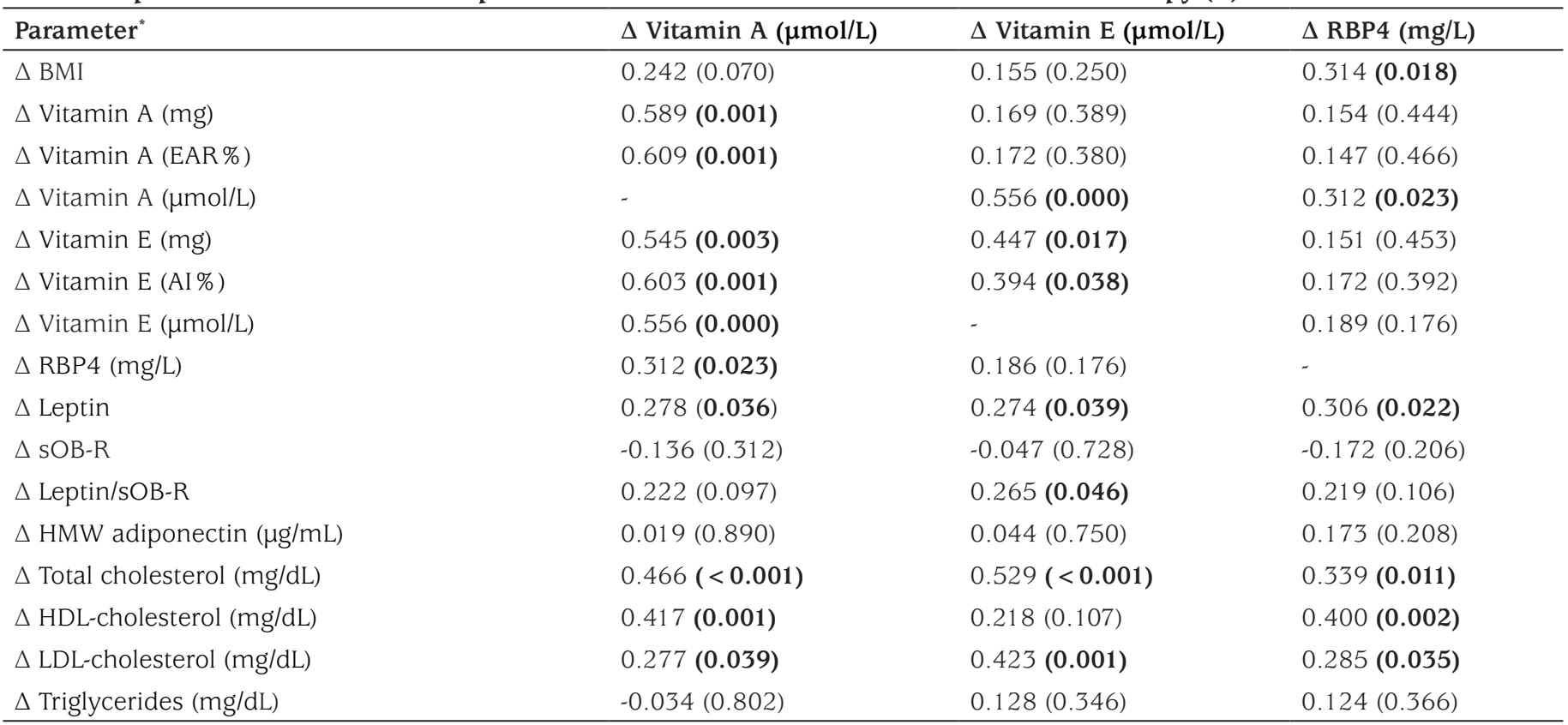

* Results are presented as Spearman's rho ( $\mathrm{p}$ value)

BMI: body mass index, HMW: adiponectin, high molecular weight adiponectin, sOB-R: soluble leptin receptor, RBP4: retinol-binding protein 4, HDL: highdensity lipoprotein, LDL: low-density lipoprotein

Table 4. Stepwise forward linear regression for changes in retinol-binding protein 4 and changes in anthropometric and biochemical parameters after three-month therapy $(\Delta)$

\begin{tabular}{|c|c|c|c|c|c|c|}
\hline \multirow[t]{2}{*}{ Variable } & \multicolumn{3}{|c|}{ Univariate analysis } & \multicolumn{3}{|c|}{ Multivariate analysis } \\
\hline & $\beta$ & $95 \%$ CI for $\beta$ & $p$ value & $\beta$ & $95 \%$ CI for $\beta$ & $p$ value \\
\hline$\triangle \mathrm{BMI}$ & 1.610 & $(0.464 ; 2.755)$ & 0.007 & 1.494 & $(0.356 ; 2.631)$ & 0.011 \\
\hline$\Delta$ Leptin & 0.140 & $(0.008 ; 0.271)$ & 0.037 & - & - & - \\
\hline$\Delta$ Total cholesterol (mg/dL) & 0.104 & $(0.042 ; 0.165)$ & 0.001 & 0.072 & $(0.010 ; 0.133)$ & 0.023 \\
\hline
\end{tabular}

BMI: body mass index, CI: confidence interval

obese children than in normal-weight children, but these values for vitamin A were within the reference range (0.8$2.8 \mu \mathrm{mol} / \mathrm{L}$ ) (28). In addition, both study groups differed significantly in terms of body composition (mainly fat mass), diet, and biochemical parameters, including the lipid profile. Although we found that the median of total energy intake was below the percentage of EER for obese and non-obese children, there were nevertheless differences in the diet composition of both groups. Obese children consumed significantly more fat and carbohydrates than children with normal body weight. In addition, we found differences in lipid profile between both groups. Obese children had higher values of triglycerides and lower values of HDL-cholesterol than the control group. The changes in the lipid profile, associated with abdominal obesity, often accompany childhood obesity $(26,27)$.
Data on vitamin E concentration in obese children are also contradictory, as both lower and normal levels have been observed $(7,26,29)$. Gunanti et al (7) found an association between lower serum concentrations of vitamin $\mathrm{E}$ and high adiposity in Mexican-American children (8-15 years of age). However, we observed similar values of vitamin $\mathrm{E}$ as well as vitamin E/lipids ratio in obese and non-obese children, despite the differences in body composition and lipid profile of these two groups and these vitamin $\mathrm{E}$ concentrations were above the deficiency cut-off value of $12 \mu \mathrm{mol} / \mathrm{L}$ in both groups. Overweight, abdominal obesity and lipid profile markers have been described in Brazilian adolescents (26). According to Albuquerque et al (26), vitamin E status was not associated with dyslipidemia in these patients.

In children who lost about $10 \%$ of their body weight after three months of lifestyle intervention, we observed 
a significant improvement in their dietary composition, i.e. a reduction in total energy intake and a reduction in carbohydrate and fat intakes. In patients who complied with the recommendations, we observed favorable changes, not only in the values of anthropometric parameters, but also in biochemical parameters, such as the levels of triglycerides or the adipokines which were investigated. Similar to Guerendiain et al (30), we observed higher vitamin E/lipids and vitamin A/lipids ratios in patients with weight loss due to the significant reduction in triglyceride concentration. The increases in lipid-corrected alpha-tocopherol and retinol plasma levels in Spanish adolescents were associated with a reduction in adiposity and a clinically significant improvement in cardio-metabolic profiles (30).

Some authors suggest that obese children consume too little vitamin E despite their apparently elevated circulating a-tocopherol concentrations (8). According to Murer et al (31), vitamin E supplements in adequately nourished obese children decrease oxidative stress markers, suggesting that obese children routinely consume inadequate amounts of antioxidants to prevent oxidative stress. In fact, an increase in LDL oxidation as a consequence of increased oxidative stress and reduced antioxidant defences was observed in obese children $(32,33)$. In our study, higher intake of vitamin $\mathrm{E}$ was found in obese compared with non-obese children, but no relationship between intake and serum concentration of vitamin $\mathrm{E}$ was identified in obese patients. According to Traber (8), circulating alpha-tocopherol concentrations do not correlate strongly with dietary alpha-tocopherol intakes in children. Although the median value for serum vitamin $\mathrm{E}$ did not change for both studied subgroups (weight loss, without weight loss) after therapy, there was a positive association between changes in vitamin E consumption and serum concentration in the whole obese group after lifestyle intervention. In addition, children who lost weight consumed significantly less vitamin E after therapy than obese children who did not lose weight. This may suggest that during a lifestyle intervention a vitamin E deficit may appear in patients losing weight. Geiker et al (34) and Hamułka et al (35) observed a lowered alphatocopherol status in obese adults after a 6-8 week weight loss intervention. These results, coupled with overweight and low alpha-tocopherol intake, suggest that there is an increased risk of oxidative stress diseases in individuals on a reduced diet.

López-Domènech et al (36) showed that weight loss attenuates inflammation and insulin resistance and promotes the amelioration of chronic endoplasmic reticulum stress and mitochondrial dysfunction in human obesity. Our obese children, even those who significantly lost weight after three months of therapy, still had excess weight and an unbalanced pro- and anti-inflammatory adipokine profile compared to normal-weight children. Children with weight loss after therapy had a significantly lower value of the leptin/ SOB-R ratio but this ratio was still higher than the controls. Leptin has been reported to promote the accumulation of reactive oxygen species (ROS) in endothelial cells and vascular smooth muscle cells as well as to have a proatherogenic effect on macrophages via an oxidative stressdependent pathway in diabetes (37). In addition, the HMW form of adiponectin, which exhibits anti-inflammatory, antiatherogenic, and insulin-sensitizing properties, had higher values in obese children with weight loss after therapy, but these were still lower than found in normal-weight children. It is known that the exposure of adipocytes to high ROS levels suppresses the expression and secretion of adiponectin, which probably explains the findings seen in our children after the intervention (38). We also found that a greater decrease in vitamin E concentration was associated with a greater decrease in the value of the leptin/sOB-R ratio after therapy in obese children, which with longer weight loss intervention, may disrupt vitamin E status. Moreover, vitamin E concentrations may be inadequate for normal liver function in obese individuals due to the occurrence of oxidative stress and the dysregulation of liver lipoprotein secretion (39). Therefore, adequate vitamin $\mathrm{E}$ status is important in obesity to maintain healthy liver function and prevent the appearance and/or progression of fatty liver and serious forms of this disease.

Hepatic metabolism is the main regulator of both vitamin $\mathrm{E}$ as well as vitamin A in the body. RBP4, including RBP4, which distributes vitamin A from the liver to the cells, play an important role in vitamin A metabolism (40). Previous studies have shown that a low-caloric diet considerably decreased RBP4 concentrations in children and adults $(41,42)$. However, the effect was dependent on the amount of weight lost, as well as the quality and diversity of the diets (43). In our study, only a slight decrease in RBP4 levels and the RBP4/vitamin A ratio was observed and an unchanged vitamin A intake was present in obese children with weight loss after three months of therapy. In addition, no correlations were found between changes in RBP4 levels and changes in vitamin A intake as well as vitamin A concentrations in the obese group after therapy. Some authors found a positive association between RBP4 concentrations and vitamin A intake in non-obese Spanish and obese Iranian women $(18,44)$. However, a RBP4 promoter polymorphism studied in a murine model of type 2 diabetes was not associated with retinol intake (17). According to Canas et al (45), RBP4 
concentrations were not influenced by the consumption of fruit and vegetable juice concentrates in prepubertal obese boys.

In our analysis, the significant impact of the changes in BMI value and total cholesterol concentration were associated with changes in RBP4 levels in obese children after the three-month therapy. It seems that long-term weight loss therapy in obese children may affect RBP4 concentration, which may result in lower vitamin A levels in tissues. Trasino et al (46) demonstrated that even with adequate dietary vitamin A, obesity dramatically reduces vitamin A levels and signaling in multiple organs of mice and humans. So, one cannot exclude that lifestyle intervention may modulate the vitamin A status in the organs of obese subjects, due to a decrease in RBP4 concentrations associated with a decrease in BMI value during therapy.

\section{Study Limitations}

This study has several potential limitations. First, the number of participants was a limitation of this study. However, the study groups were homogenous in terms of developmental period. All participants were in the prepubertal period, and obese as well as non-obese children were characterized anthropometrically and metabolically. Second, the ELISA kit used in the study does not differentiate between holoand apo-RBP4 but evaluates the total RBP4 concentration. Apo-RBP4 is defined as RBP4 that is not bound to retinol, whereas retinol-bound RBP4 (holo-RBP4) is associated with transthyretin in plasma to prevent the loss of RBP through kidney filtration (47). For a more accurate determination of the associations, apo- and holo-RBP4 should be analyzed separately in relation to the anthropometric and biochemical parameters. In further research, the analysis of these relationships should be undertaken. Finally, the lifestyle intervention period in this study was only three months and a study of a long-term intervention is needed to verify the relationship between fat-soluble vitamin status, dietary intake and biochemical parameter levels in relation to clinical outcomes.

\section{Conclusion}

A significant effect of the changes in BMI value and total cholesterol concentration on changes in RBP4 levels in prepubertal obese children after a three-month life-style intervention was demonstrated. It seems that weight loss during long-term lifestyle intervention may affect vitamin A status, due to a decrease in RBP4 concentrations associated with a decrease in BMI value in treated obese children.
Moreover, children who lost weight consumed significantly less vitamin E during therapy than obese children who did not lose weight. Therefore, the increased risk of oxidative stress due to the vitamin E deficiency may occur in patients losing weight during long-term therapy. We suggest the necessity of further monitoring of antioxidant vitamin levels in obese children during weight loss therapy and possible supplementation, especially of vitamin E, due to the risk of vitamin deficiency resulting from decreasing vitamin intake in these patients.

\section{Ethics}

Ethics Committee Approval: The study was performed in accordance with the Helsinki Declaration for Human Research, and the study protocol was approved (No.9/18) by the Ethics Committee of the Institute of Mother and Child in Warsaw, Poland.

Informed Consent: All parents gave their written informed consent for the study.

Peer-review: Externally peer-reviewed.

\section{Authorship Contributions}

Concept: Joanna Gajewska, Design: Magdalena Chełchowska, Data Collection or Processing: Jadwiga Ambroszkiewicz, Witold Klemarczyk, Analysis or Interpretation: Joanna Gajewska, Katarzyna Szamotulska, Halina Weker, Literature Search: Jadwiga Ambroszkiwicz, Halina Weker, Writing: Joanna Gajewska, Magdalena Chełchowska.

Financial Disclosure: The authors declared that this study received no financial support.

\section{References}

1. Paltoglou G, Schoina M, Valsamakis G, Salakos N, Avloniti A, Chatzinikolaou A, Margeli A, Skevaki C, Papagianni M, KanakaGantenbein C, Papassotiriou I, Chrousos GP, Fatouros IG, Mastorakos G. Interrelations among the adipocytokines leptin and adiponectin, oxidative stress and aseptic inflammation markers in pre- and earlypubertal normal-weight and obese boys. Endocrine 2017;55:925-933. Epub 2017 Jan 16

2. Kelly AS, Ryder JR, Marlatt KL, Rudser KD, Jenkins T, Inge TH. Changes in inflammation, oxidative stress and adipokines following bariatric surgery among adolescents with severe obesity. Int J Obes (Lond) 2016;40:275-280. Epub 2015 Aug 28

3. Blaner WS. Vitamin A signaling and homeostasis in obesity, diabetes, and metabolic disorders. Pharmacol Ther 2019;197;153-178. Epub 2019 Jan 29

4. Niki E. Role of vitamin E as a lipid-soluble peroxyl radical scavenger: in vitro and in vivo evidence. Free Radic Biol Med 2014;66:3-12. Epub 2013 Apr 2

5. Paes-Silva RP, Gadelha PCFP, Lemos MDCC, Castro CMMB, Arruda IKG, Diniz ADS. Adiposity, inflammation and fat-soluble vitamins in adolescents. J Pediatr (Rio J) 2019;95:575-583. Epub 2018 Jun 29 
6. Wei X, Peng R, Cao J, Kang Y, Qu P, Liu Y, Xiao X, Li T. Serum vitamin A status is associated with obesity and the metabolic syndrome among school-age children in Chongqing, China. Asia Pac J Clin Nutr 2016;25:563-570.

7. Gunanti IR, Marks GC, Al-Mamun A, Long KZ. Low serum concentrations of carotenoids and vitamin $\mathrm{E}$ are associated with high adiposity in Mexican-American children. J Nutr 2014;144:489-495. Epub 2014 Feb 5

8. Traber MG. Vitamin E inadequacy in humans: causes and consequences. Adv Nutr 2014;5:503-514.

9. Merkiel S, Chalcarz W. Preschool diets in children from Piła, Poland, require urgent intervention as implied by high risk of nutrient inadequacies. J Health Popul Nutr 2016;35:11.

10. Paes-Silva RP, Tomiya MTO, Maio R, De Castro CMMB, Arruda IKG, Diniz ADS. Prevalence and factors associated with fat-soluble vitamin deficiency in adolescents. Nutr Hosp 2018;35:1153-1162.

11. Li KJ, Jenkins N, Luckasen G, Rao S, Ryan EP. Plasma metabolomics of children with aberrant serum lipids and inadequate micronutrient intake. PLoS One 2018;13:e0205899.

12. Aeberli I, Biebinger R, Lehmann R, Lallemand D, Spinas GA, Zimmermann MB. Serum retinol-binding protein 4 concentration and its ratio to serum retinol are associated with obesity and metabolic syndrome components in children. J Clin Endocrinol Metab 2007;92:4359-4365. Epub 2007 Aug 28

13. Abdali D, Samson SE, Grover AK. How effective are antioxidant supplements in obesity and diabetes? Med Princ Pract 2015;24:201215. Epub 2015 Mar 14

14. Tan BL, Norhaizan ME, Liew WP. Nutrients and Oxidative Stress: Friend or Foe? Oxid Med Cell Longev 2018;2018:9719584.

15. Zabetian-Targhi F, Mahmoudi MJ, Rezaei N, Mahmoudi M. Retinol binding protein 4 in relation to diet, inflammation, immunity, and cardiovascular diseases. Adv Nutr 2015;6:748-762.

16. Kotnik P, Fischer-Posovszky P, Wabitsch M. RBP4: a controversial adipokine. Eur J Endocrinol 2011;165:703-711. Epub 2011 Aug 10

17. van Hoek M, Dehghan A, Zillikens MC, Hofman A, Witteman JC, Sijbrands EJ. An RBP4 promoter polymorphism increases risk of type 2 diabetes. Diabetologia 2008;51:1423-1428. Epub 2008 May 22

18. Daneshzad E, Farsad-Naeimi A, Heshmati J, Mirzaei K, Maghbooli $Z$, Keshavarz SA. The association between dietary antioxidants and adipokines level among obese women. Diabetes Metab Syndr 2019;13:1369-1373. Epub 2019 Feb 13

19. Kułaga Z, Różdżyńska-Świątkowska A, Grajda A, Gurzkowska B, Wojtyło M, Góźdź M, Świąder-Leśniak A, Litwin M. Percentile charts for growth and nutritional status assessment in Polish children and adolescents from birth to 18 year of age. Standardy Medyczne 2015;12:119-135.

20. Jarosz M. Normy żywienia dla populacji polskiej. National Food and Nutrition Institute, Warsaw, Poland, 2017;21-211.

21. Weker H. Simple obesity in children. A study on the role of nutritional factors. Med Wieku Rozwoj 2006;10:3-191.

22. Szponar L. Album of photographs of food products. National Food and Nutrition Institute, Warsaw, Poland, 2008.

23. Gronowska-Senger A. Przewodnik metodyczny badań sposobu żywienia. Science Committee on Human Nutrition of the Polish Academy of Science, Warsaw, Poland, 2013.

24. Wajszczyk B, Chwojnowska Z, Nasiadko D, Rybaczuk M. Dieta 5.0 software for individual and group nutrition assessment and diet planning. National Food and Nutrition Institute, Warsaw, Poland, 2015.

25. Zaman Z, Fielden P, Frost PG. Simultaneous determination of vitamins $A$ and $E$ and carotenoids in plasma by reversed-phase HPLC in elderly and younger subjects. Clin Chem 1993;39:2229-2234.
26. Albuquerque MN, Diniz Ada S, Arruda IK. Elevated serum retinol and low beta-carotene but not alpha-tocopherol concentrations are associated with dyslipidemia in Brazilian adolescents. J Nutr Sci Vitaminol (Tokyo) 2016;62:73-80.

27. Ortega-Senovilla H, de Oya M, Garcés C. Relationship of NEFA concentrations to RBP4 and to RBP4/retinol in prepubertal children with and without obesity. J Clin Lipidol 2019;13:301-307. Epub 2019 Jan 23

28. Laskowska-Klita T, Chełchowska M, Ambroszkiewicz J, Gajewska J, Klemarczyk W. The effect of vegetarian diet on selected essential nutrients in children. Dev Period Med 2011;15:318-325.

29. Gajewska J, Ambroszkiewicz J, Weker H, Chełchowska M. Relations between oxidized low-density lipoproteins and fat-soluble vitamin concentrations in obese children - preliminary study. Dev Period Med 2017;21:266-271.

30. Guerendiain M, Mayneris-Perxachs J, Montes R, López-Belmonte G, Martín-Matillas M, Castellote AI, Martín-Bautista E, Martí A, Martínez JA, Moreno L, Garagorri JM, Wärnberg J, Caballero J, Marcos A, LópezSabater MC, Campoy C; EVASYON Study Group. Relation between plasma antioxidant vitamin levels, adiposity and cardio-metabolic profile in adolescents: effects of a multidisciplinary obesity programme. Clin Nutr 2017;36:209-217. Epub 2015 Nov 7

31. Murer SB, Aeberli I, Braegger CP, Gittermann M, Hersberger M, Leonard SW, Taylor AW, Traber MG, Zimmermann MB. Antioxidant supplements reduced oxidative stress and stabilized liver function tests but did not reduce inflammation in a randomized controlled trial in obese children and adolescents. J Nutr 2014;144:193-201. Epub 2013 Dec 18

32. Matusik P, Prokopowicz Z, Norek B, Olszanecka-Glinianowicz M, Chudek J, Malecka-Tendera E. Oxidative/Antioxidative status in obese and sport trained children: a comparative study. Biomed Res Int 2015;2015:315747. Epub 2015 Mar 31

33. Okur I, Tumer L, Ezgu FS, Yesilkaya E, Aral A, Oktar SO, Bideci A, Hasanoglu A. Oxidized low-density lipoprotein levels and carotid intima-media thickness as markers of early atherosclerosis in prepubertal obese children. J Pediatr Endocrinol Metabol 2013;26:657662.

34. Geiker NRW, Veller M, Kjoelbaek L, Jakobsen J, Ritz C, Raben A, Astrup A, Lorenzen JK, Larsen LH, Bügel S. Effect of low energy diet for eight weeks to adults with overweight or obesity on folate, retinol, vitamin B12, D and E status and the degree of inflammation: a post hoc analysis of a randomized intervention trial. Nutr Metab (Lond) 2018;15:24.

35. Hamułka J, Górnicka M, Sulich A, Frąckiewicz J. Weight loss program is associated with decrease $\alpha$-tocopherol status in obese adults. Clin Nutr 2019;38:1861-1870. Epub 2018 Jul 20

36. López-Domènech S, Abad-jiménez Z, Iannantuoni F, de Marañón AM, Rovira-Llopis S, Morillas C, Bañuls C, Víctor VM, Rocha M. Moderate weight loss attenuates chronic endoplasmic reticulum stress and mitochondrial dysfunction in human obesity. Mol Metab 2019;9:24-33. Epub 2018 Oct 19

37. Maingrette F, Renier G. Leptin increases lipoprotein lipase secretion by macrophages: involvement of oxidative stress and protein kinase $C$. Diabetes 2003;52:2121-2128.

38. Wang $\mathrm{CH}$, Wang $\mathrm{CC}$, Huang $\mathrm{HC}$, Wei $\mathrm{YH}$. Mitochondrial dysfunction leads to impairment of insulin sensitivity and adiponectin secretion in adipocytes. FEBS J 2013;280:1039-1050. Epub 2013 Jan 27

39. Violet PC, Ebenuwa IC, Wang Y, Niyyati M, Padayatty SJ, Head B, Wilkins K, Chung S, Thakur V, Ulatowski L, Atkinson J, Ghelfi M, Smith S, Tu H, Bobe G, Liu CY, Herion DW, Shamburek RD, Manor D, Traber MG, Levine M. Vitamin E sequestration by liver fat in humans. JCI Insight 2020;5:133309. 
40. Christou GA, Tselepis AD, Kiortsis DN. The metabolic role of retinol binding protein 4: an update. Horm Metab Res 2012;44:6-14.

41. Reinehr T, Stoffel-Wagner B, Roth CL. Retinol-binding protein 4 and its relation to insulin resistance in obese children before and after weight loss. J Clin Endocrinol Metab 2008;93:2287-2293. Epub 2008 Apr 8

42. Vink RG, Roumans NJ, Mariman EC, van Baak MA. Dietary weight loss-induced changes in RBP4, FFA, and ACE predict weight regain in people with overweight and obesity. Physiol Rep 2017;5:13450.

43. Volek JS, Phinney SD, Forsythe CE, Quann EE, Wood RJ, Puglisi MJ, Kraemer WJ, Bibus DM, Fernandez ML, Feinman RD. Carbohydrate restriction has a more favorable impact on the metabolic syndrome than a low fat diet. Lipids 2009;44:297-309. Epub 2008 Dec 12

44. Hermsdorff HH, Zulet MA, Puchau B, Bressan J, Martínez JA. Association of retinol-binding protein-4 with dietary selenium intake and other lifestyle features in young healthy women. Nutrition 2009;25:392-399. Epub 2008 Dec 4

45. Canas JA, Damaso L, Altomare A, Killen K, Hossain J, Balagopal PB. Insulin resistance and adiposity in relation to serum $\beta$-carotene levels. J Pediatr 2012;161:58-64. Epub 2012 Feb 28

46. Trasino SE, Tang XH, Jessurun J, Gudas LJ. Obesity leads to tissue, but not serum vitamin A deficiency. Sci Rep 2015;5:15893.

47. Norseen J, Hosooka T, Hammarstedt A, Yore MM, Kant S, Aryal P, Kiernan UA, Phillips DA, Maruyama H, Kraus BJ, Usheva A, Davis RJ, Smith U, Kahn BB. Retinol-binding protein 4 inhibits insulin signaling in adipocytes by inducing proinflammatory cytokines in macrophages through a c-Jun N-terminal kinase- and toll-like receptor 4-dependent and retinol-independent mechanism. Mol Cell Biol 2012;32:20102019. Epub 2012 Mar 19 